J. Lake Sci.(湖泊科学), 2021, 33(1): 102-110

DOI 10. 18307/2021.0110

(c) 2021 by Journal of Lake Sciences

\title{
鄱阳湖丰水期着生藻类群落空间分布特征
}

\author{
钱奎梅 ${ }^{1}$, 刘 $^{\text {霞 }}{ }^{* * *}$, 陈宇炜 ${ }^{3}$ \\ ( 1 : 徐州工程学院, 江苏省工业污染控制及资源化重点实验室,徐州 221018) \\ (2: 中国科学院南京地理与湖泊研究所, 南京 210008) \\ (3: 南昌工程学院, 南昌 330099)
}

\begin{abstract}
摘 要: 着生藻类一般生长位置相对稳定, 其群落分布主要受环境因素的影响, 同时, 着生藻类还是重要的水环境指示生物. 本研究对鄱阳湖丰水期 5 个典型湖区 (主航道、西部湿地、南矶湿地、撮箕湖和东南湖汉) 着生藻类的群落结构特征进行调 查,包括生物量、优势种及生物多样性, 分析影响着生藻类群落区域分布的环境因子, 以期为鄱阳湖水环境保护和水资源合 理利用提供基础资料. 结果表明:鄱阳湖着生藻类群落以硅藻、绿藻和蓝藻为主; 鄱阳湖着生藻类总生物量有着明显的区域 差异: 主航道区域的生物量相对最高, 平均为 $419 \mathrm{mg} / \mathrm{m}^{2}$; 其次是东南湖汉, 平均为 $322 \mathrm{mg} / \mathrm{m}^{2}$; 南矶湿地和西部湿地分别为 172 和 $52 \mathrm{mg} / \mathrm{m}^{2}$; 而撮箕湖的总生物量相对最低, 为 $9 \mathrm{mg} / \mathrm{m}^{2}$. 主航道的着生藻类优势种群为绿藻和硅藻, 西部湿地、南矶湿 地、撮箕湖和东南湖汉 4 个区域的优势种群为硅藻. 冗余分析结果显示鄱阳湖丰水期着生藻类群落分布与总磷、电导率、 $\mathrm{pH}$ 值、总氮、硝态氮和悬浮物等理化因子关系较为密切. 鄱阳湖主航道与长江连通, 水体流速高; 西部湿地、南矶湿地、撮箕湖和 东南湖汉为季节性连通湖泊, 丰水季节与主湖区水体连为一体, 枯水季节独立蓄水. 5 个湖区的区域差异是导致其着生藻类 群落结构差异的重要原因之一. 着生藻类的多样性指数分析表明鄱阳湖水体处于中度污染状态.
\end{abstract}

关键词: 鄱阳湖;着生藻类群落;丰水期;空间分布

\section{Spatial distribution characteristics of periphytic algae community of Lake Poyang in the high water level phase*}

\section{Qian Kuimei ${ }^{1}$, Liu Xia ${ }^{2 * *} \&$ Chen Yuwei $^{3}$}

(1: Jiangsu Key Laboratory of Industrial Pollution Control and Resource Reuse, Xuzhou University of Technology, Xuzhou 221018, P.R.China)

(2: Nanjing Institute of Geography and Limnology, Chinese Academy of Sciences, Nanjing 210008, P.R.China)

(3: Nanchang Institute of Technology, Nanchang 330099, P.R. China)

Abstract: Periphytic algae usually attached stably on the substrate, and its community structure is mainly affected by environmental factors. Meanwhile, periphytic algae are important biological indicators of aquatic environment. In this study, we examined the community structure of periphytic algae in the high water level phase in 5 different areas of Lake Poyang (the main channel area, West wetland, Nanji wetland, Cuoji Lake, and Southeast Lake), including biomass, dominant species, and biodiversity. The relationship between environment and periphytic algae was analyzed. This study can provide basic data for aquatic environment protection and water resources use of Lake Poyang. The results show that Bacillariophyta, Chlorophyta, and cyanobacteria are dominant in the periphytic algae community of Lake Poyang. There are obvious spatial differences of periphytic algae biomass in Lake Poyang. The biomass of periphytic algae in the main channel is highest, averagely $419 \mathrm{mg} / \mathrm{m}^{2}$; followed by Southeast Lake, averagely 322 $\mathrm{mg} / \mathrm{m}^{2}$. The average biomass of periphytic algae in the Nanji wetland and West wetland are 172 and $52 \mathrm{mg} / \mathrm{m}^{2}$, respectively. The biomass of periphytic algae in the main channel is lowest, averagely $9 \mathrm{mg} / \mathrm{m}^{2}$. The dominant populations of periphytic algae in the main channel are Bacillariophyta and Chlorophyta, while the dominant populations in the other four regions, i.e. West wetland,

* 2020-03-29 收稿;2020-05-08 收修改稿.

国家自然科学基金项目 (31600345,41671096)、徐州工程学院教研课题 (YGJ2023) 和江苏省高等学校自然科学研 究重大项目 (19KJA580002) 联合资助.

** 通信作者; E-mail:xliu@ niglas.ac.cn. 
Nanji wetland, Cuoji Lake, and Southeast Lake, are Bacillariophyta. The redundancy analysis showed that the distribution of periphytic algae community in the high water level phase in Lake Poyang is closely related to physical and chemical factors such as total phosphorus, electrical conductivity, $\mathrm{pH}$ value, total nitrogen, nitrate nitrogen, and suspended solids. The main channel of Lake Poyang is connected to the Yangtze River with high water flow velocity. West wetland, Nanji wetland, Cuoji Lake, and Southeast Lake are seasonally connected with Lake Poyang. They are connected to the main body of Lake Poyang in the high water level phase and are separate regions in the low water level phase. The different regional characteristics of five regions are one of the important reasons for the spatial variations of periphytic algae community structure. The diversity index of periphytic algae indicated that the water body of Lake Poyang is in a moderately polluted state.

Keywords: Lake Poyang; periphytic algae community; high water level phase; spatial distribution

着生藻类 (periphytic algae) 也被称为周丛藻类, 是附着在水体基质上生活的一些微型藻类. 着生藻类是水 体中重要的初级生产者, 对于水生环境的固碳、初级生产力、养分循环和食物网都十分重要 ${ }^{[1,2]}$. 同时, 着生藻 类在湿地漫滩中比浮游植物对初级生产力的贡献更大 ${ }^{[3]}$. 着生藻类受到水流的影响较小, 对水环境变化快速 敏感, 是理想的水环境监测生物指标, 并已被广泛用于海洋、湖泊及河流等水体的生物监测中 ${ }^{[4-6]}$. 由于着生藻 类固定在一定位置,在流速较大的水体中,它们能比浮游植物更为准确地反映水质状况 ${ }^{[7]}$.

鄱阳湖是中国最大的吞吐性、季节性和通江性淡水湖泊,鄱阳湖上承赣、抚、信、饶、修五河之水,下接长 江, 水位受 “五河” 人湖水量和长江水位顶托双重影响, 年内水位变幅巨大, 在我国淡水湖泊中具有独特性和 唯一性. 鄱阳湖河湖转换会导致鄱阳湖湿地出现不同的区域特性,而这会导致不同区域的着生藻类有不同 的群落结构特征. 近年来,鄱阳湖部分湖区已经出现富营养化现象,蓝藻水华在鄱阳湖主航道都昌水域、康 山湖、撮箕湖、战备湖等湖区水面均被发现 ${ }^{[8]}$. 有关翻阳湖的生物监测已经有很多报道, 但大部分是以浮游 植物、浮游动物以及原生动物作为监测指标 ${ }^{[9-11]}$; 对于鄱阳湖着生藻类的分布情况鲜见报道, 仅吴召仕等 ${ }^{[12]}$ 报道了鄱阳湖局部湖区的水网藻水华现象,而近 20 年来有关鄱阳湖着生藻类的资料几乎为空白. 为了解和 丰富鄱阳湖着生藻类背景资料, 本研究于 2017 年 7-8 月对鄱阳湖不同湖区的着生藻类群落结构和分布特 征进行分析, 同时对水环境因子进行监测, 对鄱阳湖的水质状况进行分析评价, 旨在为鄱阳湖水环境保护和 水资源合理利用提供基础资料.

\section{1 材料与方法}

根据鄱阳湖丰枯季节水域的变化, 选择鄱阳湖 5 个典型水情区域 ( A : 主航道; B : 西部湿地; C: 南矶湿 地; D: 撮箕湖; $\mathrm{E}$ : 东南湖汉) (各个湖区的特点见表 1), 于 2017 年 7-8 月 (丰水期) 在鄱阳湖进行采样监测 (图 1). 各个湖区的采样设置见表 1. 野外现场采样时, 利用 YSI $6600 \mathrm{~V} 2$ 多参数水质监测仪测定透明度、水 温、溶解氧、电导率、 $\mathrm{pH}$ 值等指标. 同时采集 $10 \mathrm{~L}$ 水样带回实验室分析悬浮颗粒物 $(\mathrm{SS})$ 、氨氮 $\left(\mathrm{NH}_{3}-\mathrm{N}\right)$ 、硝 态氮 $\left(\mathrm{NO}_{3}^{-}-\mathrm{N}\right)$ 、正磷酸盐磷 $\left(\mathrm{PO}_{4}^{3-}-\mathrm{P}\right)$ 、总氮 $(\mathrm{TN})$ 和总磷 $(\mathrm{TP})$ 等参数. 各指标具体测定方法参照《湖泊富营

表 1 常规采样点布置方案

Tab.1 Layout scheme of general sampling sites

\begin{tabular}{|c|c|c|}
\hline 湖区 & 特点 & 采样点设置 \\
\hline A & $\begin{array}{l}\text { 鄱阳湖与长江连通的主航道区域, 从松门山至湖口, 代 } \\
\text { 表高流速湖区 }\end{array}$ & $\begin{array}{l}\text { 均匀布设 } 3 \text { 个采样点, 分别在星子、蛤蟆石及 } \\
\text { 湖口 }\end{array}$ \\
\hline B & $\begin{array}{l}\text { 西部湿地 (吴城附近), 季节性连通湖泊, 与鄱阳湖水位 } \\
\text { 存在高水位一致性、中水位相关性、低水位不相关 }\end{array}$ & $\begin{array}{l}\text { 布设 } 2 \text { 个采样点, 分别在蚌湖和吴城附近的植 } \\
\text { 被区 }\end{array}$ \\
\hline C & $\begin{array}{l}\text { 南矶湿地, 是鄱阳湖典型的水陆交错带, 丰水期为湖泊, } \\
\text { 咕水期为沼泽、泥滩浅水 }\end{array}$ & 均匀布设 5 个采样点 \\
\hline $\mathrm{D}$ & 撮箕湖,代表低流速湖区 & 布设 2 个采样点, 分别在两个湖汉 \\
\hline $\mathrm{E}$ & $\begin{array}{l}\text { 东南湖汉, 涨水期受两条上游河流冲刷作用较大, 枯水 } \\
\text { 期为沼泽、泥滩浅水 }\end{array}$ & $\begin{array}{l}\text { 在每个人湖河口位置及湖区中央各设置 } 1 \text { 个采 } \\
\text { 样点 }\end{array}$ \\
\hline
\end{tabular}




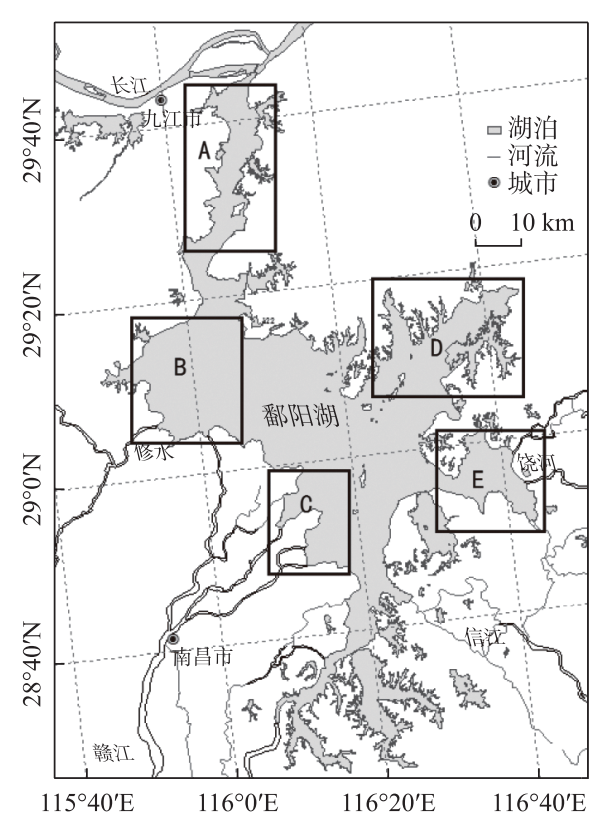

图 1 鄱阳湖采样区域分布

Fig.1 Distribution of the sampling areas in Lake Poyang

养化调查规范》 ${ }^{[13]}$.

着生藻类采用以下方法进行采样 ${ }^{[14-15]}$ : 在湖泊中选择附有藻类的石块, 用毛刷将石块上藻类刮到样品 瓶中,并用蒸馏水将基质冲洗多次,用鲁哥氏液固定, 定容到 $100 \mathrm{~mL}$, 同时量取刮下着生藻类的石块面积. 将 处理好的着生藻类样品在显微镜下观察, 用面积为 $20 \mathrm{~mm} \times 20 \mathrm{~mm}$ 、容量为 $0.1 \mathrm{~mL}$ 的计数框计算着生藻类的 细胞丰度. 计数方法为目镜视野法, 随机计数 500 个视野, 并使视野均匀分布在计数框内. 每个样品计数 2 片, 取其平均值为最终结果 (若 2 片计数结果相差 $15 \%$ 以上, 则进行第 3 片计数, 选择其中个数相近的 2 片 取平均值). 着生藻类定性定量分析参照 《中国淡水藻类——系统、分类及生态 $~^{[16]}$ 和《藻类学》 ${ }^{[17]}$, 最后计 算出基质上每个采样点的藻丰度 $\left(\mathrm{cells} / \mathrm{m}^{2}\right)$. 着生藻类生物量按照《淡水浮游生物研究方法 ${ }^{[18]}$ 计算, 假定 藻类比重为 1 ,采用细胞体积转化法计算单位面积内藻类生物量 $\left(\mathrm{mg} / \mathrm{m}^{2}\right)$.

生物多样性分析采用 Shannon-Wiener 多样性指数 ${ }^{[19]}$ :

$$
H^{\prime}=-\sum \frac{n_{i}}{N} \ln \frac{n_{i}}{N}
$$

式中, $n_{i}$ 为 $i$ 种藻类的个体数, $N$ 为群落中全部藻类的个体数 ${ }^{[18]}$.

Pielou 均匀度指数:

$$
J=H^{\prime} / H_{\text {max }}=\left(-\sum p_{i} \ln p_{i}\right) / \ln S
$$

式中, $S$ 为物种数目, $p_{i}$ 为属于 $i$ 种的个体数占全部藻类个体数的比例.

物种丰富度指数:

$$
d_{\text {Мa }}=(S-1) / \ln N
$$

式中, $S$ 为物种数目, $N$ 为所有物种的个体数之和.

使用 SigmaPlot (12.0版) 软件制作图表, 使用 SPSS 17.0 软件进行不同水域的着生藻类差异显著性分 析,利用 R 语言的 vegan 包进行着生藻类与环境因子之间的圥余分析. 


\section{2 结果}

\section{1 鄱阳湖不同湖区水体的理化指标}

鄱阳湖不同湖区水体的理化指标如图 2 所示. 采样期间的水温介于 $27.5 \sim 30.8^{\circ} \mathrm{C}$ 之间, 5 个湖区的 透明度相差不大,介于 $0.4 \sim 0.9 \mathrm{~m}$ 之间. 西部湿地 (B 区域) 的电导率相对较高, 而主航道区域 (A 区 域) 的电导率相对较低. 5 个湖区的溶解氧浓度比 较接近,介于 $6.54 \sim 8.21 \mathrm{mg} / \mathrm{L}$ 之间. 5 个湖区水体 的 $\mathrm{pH}$ 值范围为 $6.62 \sim 7.71$. 东南湖汉 ( $\mathrm{E}$ 区域) 的 COD 相对最高, 其次为主航道区域 (A 区域), 而其 余 3 个湖区相差不大. 南矶湿地 (C 区域) 与撮箕湖 (D 区域) 的 $\mathrm{TN} 、 \mathrm{NH}_{3}-\mathrm{N}$ 以及 $\mathrm{NO}_{3}^{-}-\mathrm{N}$ 浓度相对较高, 南矶湿地 ( $C$ 区域) 的总氮平均值为 $2.12 \mathrm{mg} / \mathrm{L}$, $\mathrm{NH}_{3}-\mathrm{N}$ 平均值为 $0.68 \mathrm{mg} / \mathrm{L}, \mathrm{NO}_{3}^{-}-\mathrm{N}$ 平均值为 0.76 $\mathrm{mg} / \mathrm{L}$. 而相对来说西部湿地 (B 区域) 的 $\mathrm{TN} 、 \mathrm{NH}_{3}-\mathrm{N}$ 以及 $\mathrm{NO}_{3}^{-}-\mathrm{N}$ 的浓度相对较低, $\mathrm{TN}$ 平均值为 1.22 $\mathrm{mg} / \mathrm{L}, \mathrm{NH}_{3}-\mathrm{N}$ 平均值为 $0.27 \mathrm{mg} / \mathrm{L}, \mathrm{NO}_{3}^{-}-\mathrm{N}$ 平均值为 $0.31 \mathrm{mg} / \mathrm{L}$. 主航道区域 (A 区域) 的 TP 浓度相对较 高, 为 $0.294 \mathrm{mg} / \mathrm{L}$.

\section{2 鄱阳湖着生藻类群落组成}

鄱阳湖着生藻类共检出 6 门 67 属 101 种, 其中 绿藻门 34 属 60 种, 占总藻类的 $59.4 \%$; 硅藻门 17 属 20 种, 占总藻类的 $19.8 \%$; 蓝藻门 6 属 13 种, 占 总藻类的 $12.9 \%$; 裸藻门 4 属 5 种, 占 $4.9 \%$; 甲藻门 和隐藻门分别为 1 属 1 种和 1 属 2 种, 占鄱阳湖着 生藻类总藻类的 $1.0 \%$ 和 $2.0 \%$. 不计着生藻类相对 生物量小于 $1 \%$ 的种类, 硅藻门相对生物量高达 $41 \% \sim 94 \%$, 其次为绿藻 ( $32 \% \sim 53 \%$ ).

\section{3 鄱阳湖不同湖区着生藻类的生物量比较及优势 种分布}

鄱阳湖各个水域的着生藻类生物量存在着明显 的差异 (表 2). 主航道区域 (A 区域) 着生藻类生物 量相对最高, 平均为 $419 \mathrm{mg} / \mathrm{m}^{2}$; 其次是东南湖汉 ( $\mathrm{E}$ 区域), 为 $322 \mathrm{mg} / \mathrm{m}^{2}$; 而撮箕湖 (D 区域) 的总生物 量相对最低, 为 $9 \mathrm{mg} / \mathrm{m}^{2}$. 鄱阳湖着生藻类丰度有着 明显的区域差异 (表 2). 南矶湿地 (C 区域) 着生藻

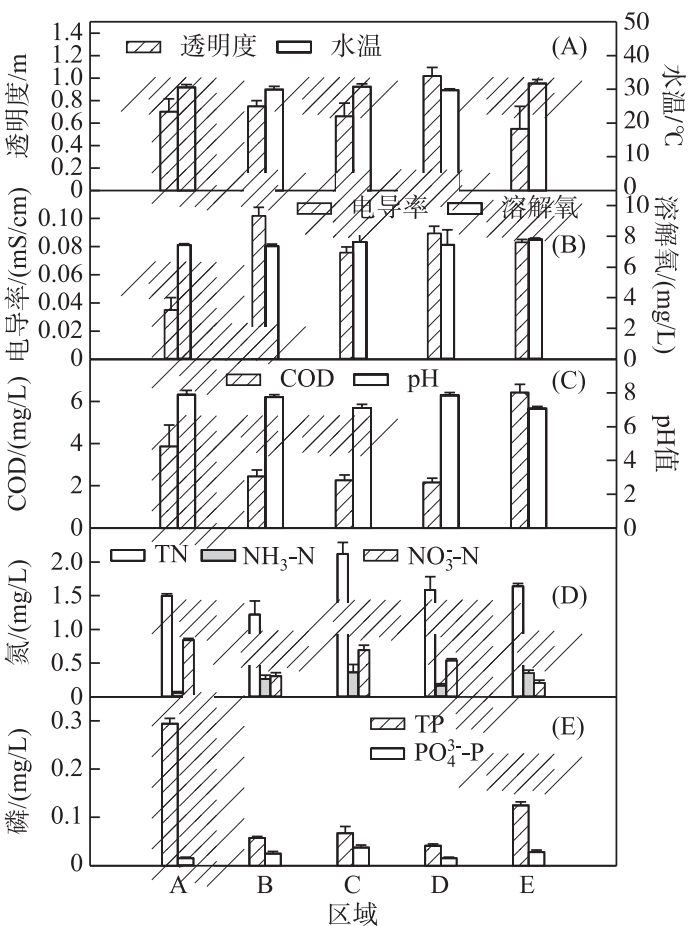

图 2 鄱阳湖水体理化指标的区域差异

Fig.2 The spatial variation of physical and chemical indicators of water in Lake Poyang

表 2 鄱阳湖不同区域着生藻类 总生物量和丰度差异

Tab.2 Biomass and abundance differences of periphytic algae in different regions of Lake Poyang

\begin{tabular}{ccc}
\hline 区域 & 生物量 $/\left(\mathrm{mg} / \mathrm{m}^{2}\right)$ & 丰度 $/\left(\right.$ cells $\left./ \mathrm{m}^{2}\right)$ \\
\hline $\mathrm{A}$ & $419 \pm 12^{\mathrm{e}}$ & $52983 \pm 3609^{\mathrm{c}}$ \\
$\mathrm{B}$ & $52 \pm 1^{\mathrm{b}}$ & $5767 \pm 347^{\mathrm{a}}$ \\
$\mathrm{C}$ & $172 \pm 5^{\mathrm{c}}$ & $63603 \pm 659^{\mathrm{d}}$ \\
$\mathrm{D}$ & $9 \pm 2^{\mathrm{a}}$ & $856 \pm 328^{\mathrm{a}}$ \\
$\mathrm{E}$ & $322 \pm 9^{\mathrm{d}}$ & $46631 \pm 545^{\mathrm{b}}$ \\
\hline
\end{tabular}

*不同小写字母代表具有显著性差异 $(P \leqslant 0.05)$. 类丰度相对最高, 平均为 $63603 \mathrm{cells} / \mathrm{m}^{2}$; 其次为主航道区域 (A 区域), 平均为 $52983 \mathrm{cells} / \mathrm{m}^{2}$; 西部湿地 (B 区域) 和撮箕湖 (D 区域) 相对最低,分别为 5767 和 $856 \mathrm{cells} / \mathrm{m}^{2}$.

鄱阳湖不同水域着生藻类的群落结构存在着明显的差异 (图 3). 就生物量而言, 硅藻在西部湿地 (B 区 域)、南矶湿地 ( C 区域)、撮箕湖 ( D 区域)、东南湖汊 ( $\mathrm{E}$ 区域) 4 个区域最高,其中,撮箕湖( D 区域) 硅藻的 相对生物量为 94\%, 而其余几个区域硅藻的相对生物量为 41\% 56\%. 绿藻在主航道区域 (A 区域) 的相对 生物量最高, 为 $54 \%$, 其次为硅藻 $(44.5 \%)$. 就丰度而言, 绿藻在 A、B 两个区域的相对丰度较高, 分别为 $65.77 \%$ 和 $50.94 \%$, 而蓝藻在南矶湿地 (C 区域)、撮箕湖 ( D 区域) 和东南湖汉 ( E 区域) 3 个区域的相对丰度 


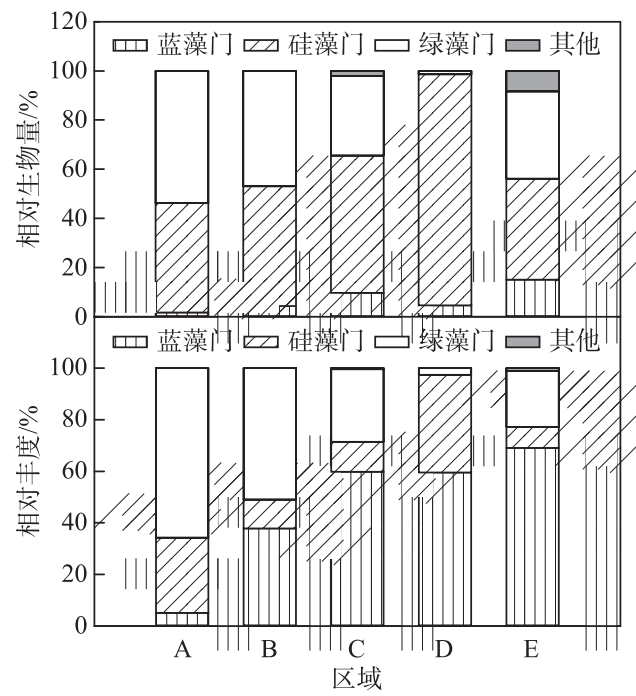

图 3 鄱阳湖各门类着生藻类生物量和 丰度的区域差异

Fig.3 Spatial variation of biomass and abundance of each phylum periphytic algae in Lake Poyang

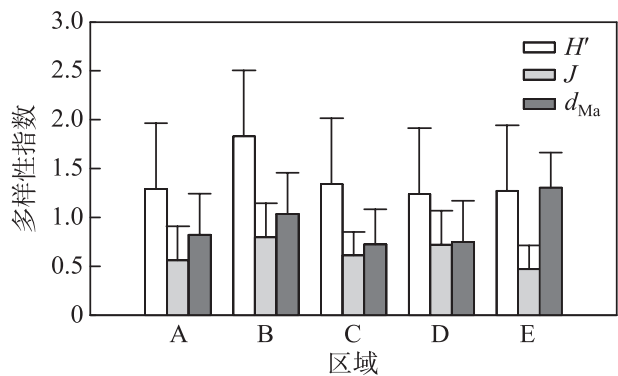

图 4 鄱阳湖着生藻类 Shannon-Wiener 种类多样性指数 $\left(H^{\prime}\right) 、$ Pielou 均匀度指数 $(J)$

及物种丰富度指数 $\left(d_{\mathrm{Ma}}\right)$ 的区域差异

Fig.4 The spatial variation of Shannon-

Wiener species diversity index $\left(H^{\prime}\right)$,

Pielou evenness index $(J)$ and

species richness index $\left(d_{\mathrm{Ma}}\right)$

of periphytic algae in Lake Poyang

表 3 鄱阳湖不同水域的着生藻类群落结构与 环境因子的典范对应分析结果

Tab.3 Summarized results for the first four axes of the CCA of species-environment

\begin{tabular}{ccccc}
\hline 项目 & 轴 1 & 轴 2 & 轴 3 & 轴 4 \\
\hline 特征值 & 0.0293 & 0.0080 & 0.0020 & 0.0003 \\
累积贡献率/\% & 73.93 & 94.10 & 99.16 & 99.89 \\
\hline
\end{tabular}

较高, 分别为 $59.86 \% 、 59.47 \%$ 和 $69.05 \%$. 硅藻门常见属 有脆杆藻、针杆藻、舟形藻、异极藻、布纹藻、羽纹藻、直链 藻、小环藻, 其优势种为中型脆杆藻 (Fragilaria intermedia), 尖针杆藻 (Synedra acus)、短小舟形藻 (Navicula exigua)、弯羽纹藻 (Pinnularia gibba)、颗粒直链 藻 (Aulacoseira granulata) 和粗壮 双菱藻 (Surirella robusta); 绿藻门常见属有鞘藻、转板藻、刚毛藻、丝藻、棒 形鼓藻, 其优势种为普林鞘藻 (Oedogonium pringsheimii); 蓝藻门常见属有鱼腥藻、微囊藻、束丝藻、浮丝藻、颤藻, 其优势种为固氮鱼腥藻 (Anabaena azotica) 、阿氏浮丝藻 (Planktothrix agardhii)、铜绿席藻 (Phormidium aerugineocoeruleum) 和鱼害微囊藻 (Microcystis ichthyoblabe).

\section{4 着生藻类群落多样性及水质评价}

鄱阳湖 5 个区域着生藻类的 Shannon-Wiener 生物多 样性指数在 $1.18 \sim 1.89$ 之间, 其中西部湿地 (B 区域) 的 Shannon-Wiener 种类多样性最高, 平均为 1.83 , 其余几个 区域相差不大, 为 $1.18 \sim 1.40$, 总体处于中等污染状态. 主 航道区域 (A 区域)、西部湿地 (B 区域)、南矶湿地 ( C 区 域) 和撮箕湖 ( D 区域) 的均匀度指数为 $0.45 \sim 0.82$, 属轻 度污染状态; 东南湖汉 ( $\mathrm{E}$ 区域) 的 Pielou 均匀度指数最 小, 说明该区域处于中污染状态. 东南湖汊 (E 区域) 和西 部湿地 ( B 区域) 的物种丰富度指数较大, 说明这两个区 域处于中污染状态 (图 4).

\section{5 着生藻类群落结构与环境因子的关系}

对鄱阳湖 5 个不同区域水环境状况主导因子与丰水 期着生藻类属种进行圥余分析, 以辨识影响丰水期着生 藻类群落特征的主要水环境因子. 结果表明,第 1 排序轴 和第 2 排序轴的特征值分别为 0.0293 和 0.0080 , 它们共 解释了丰水期不同水域着生藻类累积方差值的 $94.10 \%$ (表 3 ), 由此表明第 1 排序轴和第 2 排序轴能够真实反映 主导因子对丰水期着生藻类水域分布的影响程度, 并且 第 1 排序轴较第 2 排序轴与主导因子的相关性更好; 因 此, 第 $1 、 2$ 排序轴能够真实地反映环境因子对着生藻类 区域分布的影响情况. 从箭头的连线长度 (图 5 ) 可以看 出, 主导因子对丰水期着生藻类区域分布的相关性大小 为: $\mathrm{TP}>$ 电导率 $>\mathrm{pH}$ 值 $>$ 透明度 $>\mathrm{NH}_{3}-\mathrm{N}>\mathrm{COD}>\mathrm{NO}_{3}^{-}-\mathrm{N}>$ 水 温 $>\mathrm{SS}>\mathrm{TN}>\mathrm{PO}_{4}^{3-}-\mathrm{P}$. 其中, $\mathrm{TP} 、 \mathrm{NO}_{3}^{-}-\mathrm{N} 、 \mathrm{NH}_{3}-\mathrm{N}$ 和 $\mathrm{COD}$ 对 绿藻群落分布的影响程度显著, TP、SS 和电导率对硅藻 群落分布的影响程度显著, 透明度、 $\mathrm{pH}$ 值、水温和电导率 对蓝藻群落分布的影响程度显著. 因此, TP、电导率、 $\mathrm{pH}$ 值、 $\mathrm{TN} 、 \mathrm{NO}_{3}^{-}-\mathrm{N}$ 和 $\mathrm{SS}$ 等理化因子是影响鄱阳湖丰水期着 生藻类群落分布的主要环境因子. 鄱阳湖的 5 个湖区分 别分布在不同的象限, 主航道 (A 区域) 主要分布于横轴 下方第 3 象限内, 西部湿地 (B 水域) 分布于横轴下方第 3 
和 4 象限内, 南矶湿地 ( $\mathrm{C}$ 水域) 分布于第 2 象限内, 撮箕湖 (D 水域) 主要分布于第 1 和 4 象限内, 东南湖汉 (E 水域) 分布于第 2 象限内 (图 5).

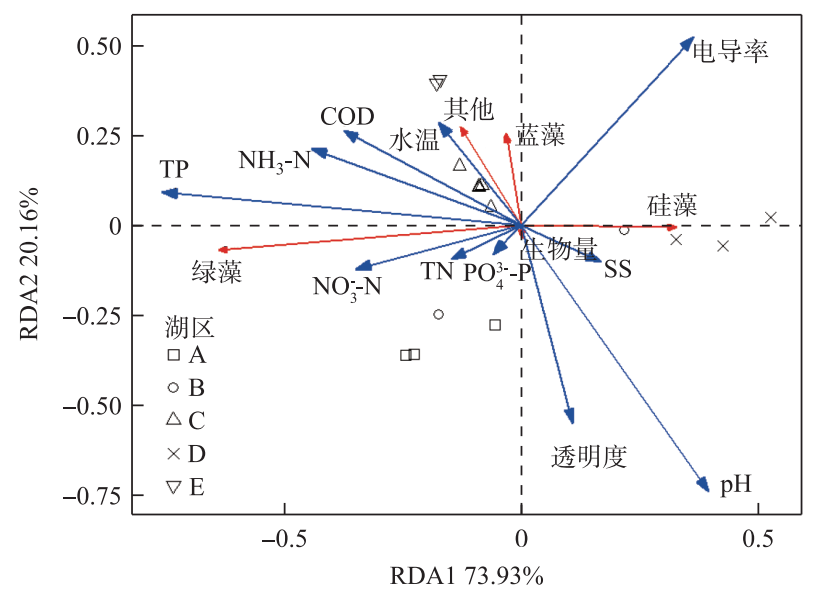

图 5 鄱阳湖不同水域的着生藻类群落结构与环境因子的冗余分析

Fig.5 The redundancy analysis of periphytic algae community structures and environmental variables in Lake Poyang

\section{3 讨论}

鄱阳湖是中国最大的吞吐性、季节性和通江性淡水湖泊, 其水位受 “五河” 入湖水量和长江水位顶托双 重影响,年内水位变幅巨大, 会导致鄱阳湖出现河湖转换的奇特景观, 从而改变鄱阳湖的重要生境一一水陆 交错带的环境特征, 进而会对其中的着生藻类产生巨大的影响. 本研究中, A 区域为鄱阳湖与长江连通的主 航道, 从松门山至湖口, 代表高流速湖区; B 区域为西部湿地 (吴城附近), 季节性连通湖泊, 与鄱阳湖水位存 在高水位一致性、中水位相关性、低水位不相关; C 区域为南矶湿地, 丰水期为湖泊,枯水期为沼泽、泥滩浅 水; $\mathrm{D}$ 区域为撮箕湖, 为典型的碟形洼地, 是鄱阳湖典型的水陆交错带, 丰水季节与主湖区水体连为一体, 枯 水季节独立蓄水, 水位比较稳定; $\mathrm{E}$ 区域为东南湖汉, 涨水期受两条上游河流冲刷作用较大, 枯水期为沼泽、 泥滩浅水. 这些特殊的生境对鄱阳湖湿地生态系统多样性具有极其重要的价值.

着生藻类一般存在于附生、缠结或移动的着生生物基质中, 并且由于群落中物种的组成和附着形式的 差异,可形成不同的三维结构——缠绕、附着等 ${ }^{[20]}$. A 区域为鄱阳湖与长江连通主航道, 该水域即使在枯水 期也不与鄱阳湖的大湖面断开, 因此, 水流冲刷作用一直存在. 一般来说, 丝状绿藻的定植和生长速度通常 较慢, 因此它们出现在较老的植物群落中 ${ }^{[21]}$. 在主航道, 牢固附着的着生藻类占优势地位, 如鞘藻属 $(O e-$ dogonium sp.). 一般牢固附着种类在演替过程的开始就具有较强的粘附强度, 如鞘藻 (Oedogonium sp.) 通常 附着在牢固的基质上 ${ }^{[22]}$. 同时, 这些物种在演替过程中还可以作为附着基质,为其他种类定植提供支撑或 附着基质,这种方式使得它们不容易受到水流的物理扰动影响 ${ }^{[23]}$. 高水位时期,在热分层条件影响下,丝状 绿藻鞘藻会形成优势种群, 因为它们一般垂直生长, 从而能够接受到更多的光照和营养物质 ${ }^{[24]}$. 另外, 夏季 较强烈的光照和较高的水温会促进丝状绿藻 (如鞘藻) 的生长 ${ }^{[22]}$. 因此, 主航道的着生藻类总生物量相对最 高, 且绿藻为优势种群.

无论着生藻类的原始群落结构如何, 其群落构建都是随着环境条件的变化从敏感物种转变为更耐受的 物种 ${ }^{[25]}$. Pfeiffer 等 ${ }^{[25]}$ 对多瑙河漫滩的研究表明, 水流扰动大大地改变了藻类群落, 硅藻在春季占据主导地 位, 而由丝状绿藻组成的群落在夏季迅速生长并占优势. Dunck 等 ${ }^{[24]}$ 对亚马逊巴拿马运河洪泛平原的研究 显示, 席藻 (Phormidium sp.) 和水绵 (Spirogyra sp.) 等多细胞藻类在高水位时期为优势种群, 而针脆杆藻 (Fragilaria capucina)、爪哇脆杆藻 ( F. javanica) 和鞘藻属 (Oedogonium sp.) 等牢固附着种类在低水位时期占 
优势地位. 本研究中, 西部湿地、南矶湿地、撮箕湖和东南湖汉 4 个区域的着生藻类生物量相对于主航道低, 硅藻门占优势. 这 4 个湖区在丰水期与大湖面是连通的,枯水期与大湖面隔离. 这 4 个湖区的着生藻类在鄱 阳湖的水位波动期间, 会受到涨退水的影响. 首先, 退水期间着生藻类被冲刷到下游, 待枯水期时, 着生藻类 群落以重新定植的松散附着藻类为主, 主要为具有高迁移率和繁殖率的硅藻 $(\mathrm{R} \text { 策略 })^{[26]}$, 如单细胞藻类由 于其较小的尺寸而成为优势种群, 并且由于它们具有移动能力, 促使其在着生藻类基质内位移以寻找可用 资源 ${ }^{[24]}$. 枯水期这 4 个湖区与鄱阳湖大湖面隔离, 其中的着生藻类不受水流扰动影响. 之后, 在涨水期的水 流冲刷作用下, 这些松散附着的着生藻类被冲到下游. 本研究的采样时期为丰水期, 在着生藻类的短期演替 过程中, 着生藻类同样以重新定植的松散附着藻类为主, 这与 Dunck 等 ${ }^{[24]}$ 的研究结论相同, 即高水位时期着 生藻类的优势种群以松散附着藻类为主. 这也是西部湿地、南矶湿地、撮箕湖和东南湖汉 4 个区域着生藻类 总生物较低且其主要优势种群为硅藻的原因.

着生藻类的生长受到水动力过程、营养物质、光照以及摄食等各因子的共同影响, 这些因素决定了着生 藻类的生长状态、群落结构及其空间分布的变化 ${ }^{[5,27]}$. 水位波动除了影响洪泛区湖泊中着生藻类的生物量 和丰度外 ${ }^{[28]}$, 还会对周围的着生藻类群落结构特征产生影响 ${ }^{[29]}$. 生长于湖底表面和水草表面的着生藻类被 认为是营养物质释放到水中之前的重要吸收者 ${ }^{[21]}$. 关于氮、磷等营养盐对着生藻类影响的研究较多. 多数 研究结果表明, 随着营养盐浓度的增加, 附着藻类生物量会显著增加 ${ }^{[30-33]}$. 文航等 ${ }^{[34]}$ 研究了滇池流域着生 藻类群落特征与水环境因子的相关性, 指出影响着生藻类生长和分布的主要水质因子为 $\mathrm{TN} 、 \mathrm{NH}_{3}-\mathrm{N}$ 和 $\mathrm{TP}$. 同时, 磷的富集可以导致丝状绿藻的大量生长, 是由于其具备磷的吸附一解吸机制 ${ }^{[35]}$. 本研究中冗余分析 表明, $\mathrm{TP} 、$ 电导率、 $\mathrm{pH}$ 值、 $\mathrm{TN} 、 \mathrm{NO}_{3}^{-}-\mathrm{N}$ 和 $\mathrm{SS}$ 等理化因子对鄱阳湖丰水期着生藻类群落分布影响较大.

在水体持续混合的富营养化湖泊中, 丝状绿藻为着生藻类的优势种群 ${ }^{[36-37]}$. 本研究也有类似现象, 大型 丝状绿藻鞘藻、转板藻、刚毛藻、丝藻为常见属, 鞘藻属为优势种. 有研究指出, 富营养化会导致着生藻类大 型物种的丰度高于微型物种 ${ }^{[37-39]}$. 同时, 本研究中着生藻类的优势种为中型脆杆藻 (Fragilaria intermedia) 、 尖针杆藻 (Synedra acus)、颗粒直链藻 (Aulacoseira granulata), 这些均为中等富营养化水体的典型代表 ${ }^{[36]}$, 因 此, 这也表明鄱阳湖具有一定程度的富营养化. 多样性指数是反映丰富度和均匀度的综合指标, ShannonWiener 多样性指数、Margalef 多样性指数、Simpson 多样性指数、均匀度指数等在湖库评价中应用较多 ${ }^{[40]}$. 一 般认为, Shannon-Wiener 多样性指数大于 3 时, 水体为轻污染或无污染, 指数为 $1 \sim 3$ 时为中度污染, 指数为 $0 \sim 1$ 时为重度污染 ${ }^{[40]}$. 鄱阳湖 5 个区域的 Shannon-Wiener 生物多样性指数在 $1.18 \sim 1.89$ 之间, 其中西部湿 地的 Shannon-Wiener 种类多样性最高, 其余几个区域相差不大, 为 $1.18 \sim 1.40$, 水体处于中度污染状态 ${ }^{[40]}$. 主 航道区域、西部湿地、南矶湿地和撮箕湖的均匀度指数为 $0.45 \sim 0.82$, 属轻度污染状态; 东南湖汉的 Pielou 均 匀度指数最小, 说明该区域属于中污染状态 ${ }^{[41]}$. 东南湖汉和西部湿地的物种丰富度指数较大, 说明这两个 区域属于中污染状态 ${ }^{[42]}$.

\section{4 结论}

鄱阳湖着生藻类共检出 6 门 67 属 101 种, 鄱阳湖着生藻类群落以硅藻、绿藻和蓝藻为主; 着生藻类总生 物量有着明显的区域差异: 主航道>东南湖汊 >南矶湿地>西部湿地 >撮箕湖. 呪余分析结果显示鄱阳湖丰水 期着生藻类群落分布与 $\mathrm{TP}$ 、电导率、 $\mathrm{pH}$ 值、 $\mathrm{TN} 、 \mathrm{NO}_{3}^{-}-\mathrm{N}$ 和 $\mathrm{SS}$ 等理化因子关系较为密切. 主航道的着生藻类 优势种群为绿藻和硅藻, 西部湿地、南矶湿地、撮箕湖和东南湖汉 4 个区域的优势种群为硅藻. 鄱阳湖主航 道与长江连通, 水体流速高; 西部湿地、南矶湿地、撮箕湖和东南湖汉为季节性连通湖泊, 丰水季节与主湖区 水体连为一体, 枯水季节独立蓄水. 主航道一直与鄱阳湖的大湖面连通, 而其余 4 个湖区在枯水期与大湖面 隔离, 这也是导致其着生藻类群落结构差异的重要原因. 着生藻类的多样性指数分析表明鄱阳湖水体处于 中度污染状态.

\section{5 参考文献}

[ 1 ] Daniels WC, Kling GW, Giblin AE. Benthic community metabolism in deep and shallow Arctic lakes during 13 years of whole-lake fertilization. Limnology and Oceanography, 2015, 60(5) : 1604-1618. DOI: 10.1002/lno.10120. 
[ 2 ] Guo F, Kainz MJ, Sheldon F et al. Spatial variation in periphyton fatty acid composition in subtropical streams. Freshwater Biology, 2015, 60(7) : 1411-1422. DOI: 10.1111/fwb.12578.

[ 3 ] Robinson GGC, Gurney SE, Goldsborough LG. Response of benthic and planktonic algal biomass to experimental waterlevel manipulation in a prairie lakeshore wetland. Wetlands, 1997, 17(2) : 167-181. DOI: 10.1007/BF03161407.

[ 4 ] Nayar S, Goh BPL, Chou LM. Settlement of marine periphytic algae in a tropical estuary. Estuarine, Coastal and Shelf Science, 2005, 64(2/3): 241-248. DOI: 10.1016/j.ecss.2005.01.016.

[ 5 ] Dunck B, Schneck F, Rodrigues L. Patterns in species and functional dissimilarity: Insights from periphytic algae in subtropical floodplain lakes. Hydrobiologia, 2016, 763(1) : 237-247. DOI: 10.1007/s10750-015-2379-x.

[ 6 ] Li BB, Li R, Tan Q et al. Structure of periphytic algal community and evaluation of water quality in the section from Yibin to Jiangjin in the upper Yangtze River. Journal of Southwest University: Natural Science, 2018, 40(3) : 10-17. [李斌斌, 李锐, 谭巧等. 长江上游宜宾至江津段周丛藻类群落结构及水质评价. 西南大学学报: 自然科学版, 2018,40 (3) : 10-17.]

[ 7 ] Shen YF, Zhang ZS, Gong XJ et al eds. New monitoring technique in microbiology. Beijing: China Architecture and Building Press, 1990. [ 沈蕴芬，章宗涉，龚循矩等. 微型生物监测新技术. 北京: 中国建筑工业出版社，1990.]

[ 8 ] Qian KM, Liu X, Duan M et al. Distribution and its influencing factors of bloom-forming cyanobacteria in Poyang Lake. China Environmental Science, 2016, 36(1) : 261-267. [ 钱奎梅, 刘霞, 段明等. 鄱阳湖蓝藻分布及其影响因素分析. 中国环境科学, 2016, 36(1): 261-267.]

[ 9 ] Liu X, Li YL, Liu BG et al. Cyanobacteria in the complex river-connected Poyang Lake: Horizontal distribution and transport. Hydrobiologia , 2016, 768(1) : 95-110. DOI: 10.1007/s10750-015-2536-2.

[10] Lv Q, Hu XR, Nie X et al. Impact of water level fluctuations on the succession of zooplankton in Poyang Lake. Acta Ecologica Sinica , 2020, 40(4) : 1486-1495. DOI: 10.5846/stxb201812142730 [吕乾, 胡旭仁, 聂雪等. 鄱阳湖丰水期水 位波动对浮游动物群落演替的影响. 生态学报, 2020, 40(4) : 1486-1495.]

[11] Xie QM, Li CC, Peng CL. Preliminary studies on community ecology of protozoan in Poyang Lake. Jiangxi Science, 2000, (1) : 40-44. [谢钦铭, 李长春, 彭赐莲. 鄱阳湖原生动物群落生态的初步研究. 江西科学, 2000, (1) : 40-44.]

[12] Wu ZS, Wang JL, Xia Y et al. A record of bloom in Lake Poyang Hydrodictyon reticulatum. J Lake Sci, 2014, 26(3) : 481-484. DOI: 10.18307/2014.0320. [ 吴召仕, 王卷乐, 夏颖等. 水网藻 (Hydrodictyon reticulatum) 水华在鄱阳湖的 纪录. 湖泊科学, 2014, 26(3) : 481-484.]

[13] Jin XC, Tu QY eds. Lake eutrophication investigation standard: second edition. Beijing: China Environment Science Press, 1990. [ 金相灿, 屠清瑛. 湖泊富营养化调查规范. 北京: 中国环境科学出版社, 1990. ]

[14] Robinson GGC. Methodology: The key to understanding periphyton//Wetzel RG ed. Periphyton of freshwater ecosystems. Springer Netherlands, 1983. DOI: 10.1007/978-94-009-7293-3_32.

[15] Wu Y ed. Periphyton: Functions and application in environmental remediation. Elsevier, 2017: 434.

[16] Hu HJ, Wei YX ed. The freshwater algae of China-Systematics, taxonomy and ecology. Beijing: Science Press, 2006. [胡鸿钧, 魏印心. 中国淡水藻类——系统、分类及生态. 北京: 科学出版社, 2006.]

[17] Fott B ed. Translated by Luo DA. Algenkunde. Shanghai: Shanghai Scientific \& Technical Publishers, 1980. [福迪 B 著. 罗迪安译. 藻类学. 上海: 上海科学技术出版社, 1980.]

[18] Zhang ZS, Huang XF eds. Research methods of freshwater plankton. Beijing: Science Press, 1991. [章宗涉,黄祥飞. 淡 水浮游生物研究方法. 北京: 科学出版社, 1991.]

[19] Shannon CE, Weaver W eds. The mathematical theory of communication. Urbana: University of Illinois Press, 1949.

[20] Tuji A. The effect of irradiance on the growth of different forms of freshwater diatoms: Implications for succession in attached diatom communities. Journal of Phycology, 2000, 36(4) : 659-661. DOI: 10.1046/j.1529-8817.2000.99212.x.

[21] Biggs BJF, Stevenson RJ, Lowe RL. A habitat matrix conceptual model for stream periphyton. Fundamental and Applied Limnology, 1998, 143(1) : 21-56. DOI: 10.1127/archiv-hydrobiol/143/1998/21.

[22] Albay M, Akçaalan R. Effects of water quality and hydrologic drivers on periphyton colonization on Sparganium erectum in two Turkish lakes with different mixing regimes. Environmental Monitoring and Assessment, 2008, 146(1/2/3) : 171-181. DOI: $10.1007 / \mathrm{s} 10661-007-0069-5$.

[23] Passy SI. Diatom ecological guilds display distinct and predictable behavior along nutrient and disturbance gradients in running waters. Aquatic Botany, 2007, 86(2) : 171-178. DOI: 10.1016/j.aquabot.2006.09.018. 
[24] Dunck B, Bortolini JC, Rodrigues L et al. Functional diversity and adaptive strategies of planktonic and periphytic algae in isolated tropical floodplain lake. Brazilian Journal of Botany, 2013, 36(4) : 257-266. DOI : 10.1007/s40415-013-0029-y.

[25] Pfeiffer TŽ, Mihaljević M, Špoljarić D et al. The disturbance-driven changes of periphytic algal communities in a Danubian floodplain lake. Knowledge and Management of Aquatic Ecosystems, 2015, 416(2) : 1-15. DOI: 10.1051/kmae/2014038.

[26] Algarte VM, Rodrigues L. How periphytic algae respond to short-term emersion in a subtropical floodplain in Brazil. Phycologia, 2013, 52(6) : 557-564. DOI: 10.2216/12-112.1.

[27] Algarte VM, Siqueira NS, Rodrigues L. Desiccation and recovery of periphyton biomass and density in a subtropical lentic ecosystem. Acta Scientiarum Biological Sciences, 2013, 35(3) : 311-318. DOI: 10.4025/actascibiolsci.v35i3.14022.

[28] Adame KL, Dunck B, Rodrigues L. Periphytic algal community in lentic environments of the Upper Paraná River floodplain: Seasonal and spatial variation. Acta Limnologica Brasiliensia, 2018, 30: e205. DOI: 10.1590/s2179-975x5017.

[29] Stefania B, Vanessa MA, Liliana R. Composition and taxonomic similarity of the periphytic algal community in different natural substrates in a neotropical floodplain, Brazil. African Journal of Plant Science, 2015, 9(1) : 17-24. DOI: 10. 5897/ajps2014.1239.

[30] Havens KE, East TL, JRodusky A et al. Littoral periphyton responses to nitrogen and phosphorus: An experimental study in a subtropical lake. Aquatic Botany, 1999, 63(3/4) : 267-290. DOI: 10.1016/S0304-3770(98)00121-1.

[31] Hansson LA. Factors regulating periphytic algal biomass. Limnology and Oceanography, 1992, 37(2) : 322-328. DOI: 10. 4319/lo.1992.37.2.0322.

[32] Xu H, Qin BQ, Zhu GW. Nutrient limitation of cyanobacterial growth in different regions of Lake Taihu in summer. China Environmental Science, 2012, 32(12) : 2230-2236. [许海, 秦伯强, 朱广伟. 太湖不同湖区夏季蓝藻生长的营养盐 限制研究. 中国环境科学, 2012, 32(12): 2230-2236.]

[33] Ferragut $\mathrm{C}$, de Campos BD. Effect of $\mathrm{N}$ and $\mathrm{P}$ enrichment on periphytic algal community succession in a tropical oligotrophic reservoir. Limnology, 2012, 13(1) :131-141. DOI: 10.1007/s10201-011-0367-z.

[34] Wen H, Cai JL, Su Y et al. Characteristics of periphytic algal community and its relationship with aquatic environmental factors in streams of Lake Dianchi watershed in wet season. J Lake Sci, 2011, 23(1) : 40-48. DOI: 10.18307/2011.0107. [文航, 蔡佳亮, 苏玉等. 滇池流域人湖河流丰水期着生藻类群落特征及其与水环境因子的关系. 湖泊科学, $2011,23(1): 40-48$. ]

[35] Zebek E. Succession of periphyton and phytoplankton assemblages in years with varying amounts of precipitation in a shallow urban lake (Lake Jeziorak mały, Poland). Ekologia-bratislava, 2014, 33 ( 3 ) : 259-273. DOI: 10. 2478/eko2014-0025.

[36] Reynolds CS. Scales of disturbance and their role in plankton ecology. Hydrobiologia, 1993, 249(1/2/3): 157-171. DOI: 10.1007/BF00008851.

[37] Dunck B, Felisberto SA, de Souza NI. Effects of freshwater eutrophication on species and functional beta diversity of periphytic algae. Hydrobiologia, 2019, 837( 1) : 195-204. DOI : 10.1007/s10750-019-03971-x.

[38 ] Ferragut C, Campos BD. Periphytic algal community adaptive strategies in N and P enriched experiments in a tropical oligotrophic reservoir. Hydrobiologia, 2010, 646(1) : 295-309. DOI: 10.1007/s10750-010-0168-0.

[39] Lange K, Townsend CR, Matthaei CD. A trait-based framework for stream algal communities. Ecology and Evolution, 2016, 6(1) : 23-36. DOI: $10.1002 /$ ece3.1822.

[40] Kong FX ed. Environmental biology. Beijing: High Education Press, 2000: 391. [孔繁翔. 环境生物学. 北京: 高等教 育出版社, 2000: 391.]

[41] Spatharis S, Roelke DL, Dimitrakopoulos PG et al. Analyzing the ( mis) behavior of Shannon index in eutrophication studies using field and simulated phytoplankton assemblages. Ecological Indicators, 2011, 11(2) : 697-703. DOI: 10.1016/j. ecolind.2010.09.009.

[42] Wu TH, Liu JS, Deng JM et al. Community structure of phytoplankton and bioassessment of water quality in a large watercarrying lake, Lake Hongze. J Lake Sci, 2019, 31(2) : 440-448. DOI: 10.18307/2019.0213. [吴天浩, 刘劲松, 邓建 明等. 大型过水性湖泊——洪泽湖浮游植物群落结构及其水质生物评价. 湖泊科学, 2019, 31(2): 440-448.] 